\title{
Flammability Characteristics of Animal Fibers: Single Breed Wools, Alpaca/Wool, and Llama/Wool Blends
}

\author{
Mary L. Galaska, Larry D. Sqrow, J. Douglas Wolf and Alexander B. Morgan *(i) \\ University of Dayton Research Institute, Dayton, OH 45469, USA; mary.galaska@udri.udayton.edu (M.L.G.); \\ larry.sqrow@udri.udayton.edu (L.D.S.); doug.wolf@udri.udayton.edu (J.D.W.) \\ * Correspondence: alexander.morgan@udri.udayton.edu
}

Received: 9 November 2018; Accepted: 24 December 2018; Published: 3 January 2019

\begin{abstract}
Animal protein-based fibers used in textiles often are assumed to have uniform properties independent of source, and yet are different when considering texture, structure, and color. Differences between fibers from animal species have been studied in regard to general flammability behavior, but differences between fibers from breeds of the same species have not been studied. Fibers from two sheep breeds (Jacob, CVM/Romeldale) and two camelids (Alpaca, Llama) were studied for flammability effects on fabrics hand knit from yarns made from these different fibers. A total of five different yarns were studied: 100\% Jacob, 100\% CVM/Romeldale, 100\% Alpaca, 50\% Llama/Merino wool, and 50\% Alpaca/Merino wool. Flammability was studied with cone calorimeter, microcombustion calorimeter, and vertical flame spread techniques. The results from this limited study demonstrate that there are differences between fibers from different breeds and differences between species, but the differences cannot be easily explained on the basis of inherent heat release or chemistry of the fiber. Sometimes yarn density and the tightness of the knit have more of an effect on self-extinguishment in vertical flame spread tests than does fiber heat release/chemistry. Pure Alpaca fiber, however, displays self-extinguishing behavior and low heat release when subjected to combustion conditions. This may be related to the amount of sulfur in its chemical structure, and its ability to be spun into a yarn which yields a tighter hand-knit density.
\end{abstract}

Keywords: flammability; cone calorimeter; knit fabrics; animal fibers; textiles

\section{Introduction}

Recent work has found that, in regard to flammability, animal fibers tend to show similar behavior at the milligram scale in that they melt and char, although some differences can be seen among fibers from different animal species (sheep, goat, camel, rabbit, etc.) [1]. While the chemical structure of most protein-based fibers from animals has some definite similarity [2], the fibers clearly differ between species in regard to physical structure. These differences in physical structure often translate into clear visual and textural differences (also known as "hand") when these fibers are spun into textiles. Differences in fibers between animal breeds of the same species also exist, with different sheep producing wool of greatly different visual and textural properties [3,4]. It can be assumed that the fibers produced from the same species, but different breeds, will be the same chemically, and yet they can have greatly different visual and textural properties. These textural properties could translate into flammability differences between fibers from different breeds of the same species, or they may not be significantly different. The purpose of this study was to determine if the fibers are, for all practical purposes, the same in regard to flammability, even with different breeds, or if they are different, and if different why they are different. Finding animal fibers as a function of breed per species, however, is not an easy task due to how animal fibers are typically consumed for textile use. 
Relevant to textiles, most animal fibers are blended with no regard to breed of origin, spun into fibers, and woven into textiles. Finding woven textiles where the breed (or breeds) of original animal are known is not possible, given how wool/animal fiber fabrics are processed commercially. However, in the world of hand-knit fabrics and garments, single breed spun yarns are available. While fire safety of commercial machine-woven garments is measured and regulated, hand-knit goods typically are not regulated for fire safety, and while animal fibers tend to have good fire performance in some regulatory tests, there may be value in understanding the fire safety of hand knit animal fiber garments since the fire safety of these items is unknown and unregulated. Hand-knit items are made from yarns such as those purchased and studied in this paper, and are highly variable as a function of yarn producer and the consumer of the yarns. Furthermore, determining whether there is any meaningful difference in animal fiber flammability as a function of breed of origin could result in fire safety improvements not just for hand knit items, but also for other textiles, by identifying which breeds produce lower-flammability fiber. Of course, flammability is hardly ever the main reason for picking a particular fiber for a fabric, as comfort and durability dominate selection. However, if fibers with good "hand", durability, and other desirable traits could be identified, along with inherent flammability performance, it may open up new opportunities for custom fiber blends in which a good balance of comfort and fire safety could be obtained. This may enable more use of renewable natural fibers for fire protection in textiles and furniture, rather than increasing levels of synthetics which can have higher flammability than natural fibers [5-9].

Five yarns were selected for this study, including:

- $100 \%$ Jacob (Sheep) [10]: The Jacob is from the United Kingdom, and is noteworthy for having up to four horns, regardless of sheep gender. It is a piebald breed of sheep, meaning it has dark colored areas of wool mixed in with white wool regions. An example of this sheep is shown in Figure 1a.

- $100 \%$ CVM/Romeldale (Sheep) [11]: CVM stands for California Variegated Mutant and is a sub-breed of the Romeldale breed, which is native to the United States. An example of this sheep is shown in Figure 1b.

- $100 \%$ Alpaca (Camelid) [12]: The Alpaca (Figure 2b) is native to South America and is closely related to another South American Camelid, the Llama. Alpaca come in various colors and have some distinct breeds. In the US, they are farm livestock for the purposes of collecting their wool/fibers for use in garments, mostly for hand-knit items.

- $50 \%$ Alpaca/Merino (Camelid/Sheep): It should be noted that while pure Alpaca fiber was obtained for this study, typically Alpaca is combined with wool to give the fiber some resiliency. $100 \%$ Alpaca tends to have no "memory", and so the fibers will stretch out during use of the garment/knit item, causing items made with 100\% Alpaca to sag over time. The Merino sheep is a very common breed across the world [13], and is known for the softness of its wool.

- $50 \%$ Llama/Merino (Camelid/Sheep): Similar to Alpaca fibers, Llama fibers are rarely used by themselves in yarns because the yarns have such poor "memory" and will stretch out/elongate over time. The Llama (Figure 2a) is a domesticated South American Camelid, closely related to the Alpaca, raised as livestock in South America for its soft wool used in textiles [14]. As with Alpacas, the wool is used in textiles for garments, mostly for hand-knit items in the US, and comes in a variety of natural colors. 


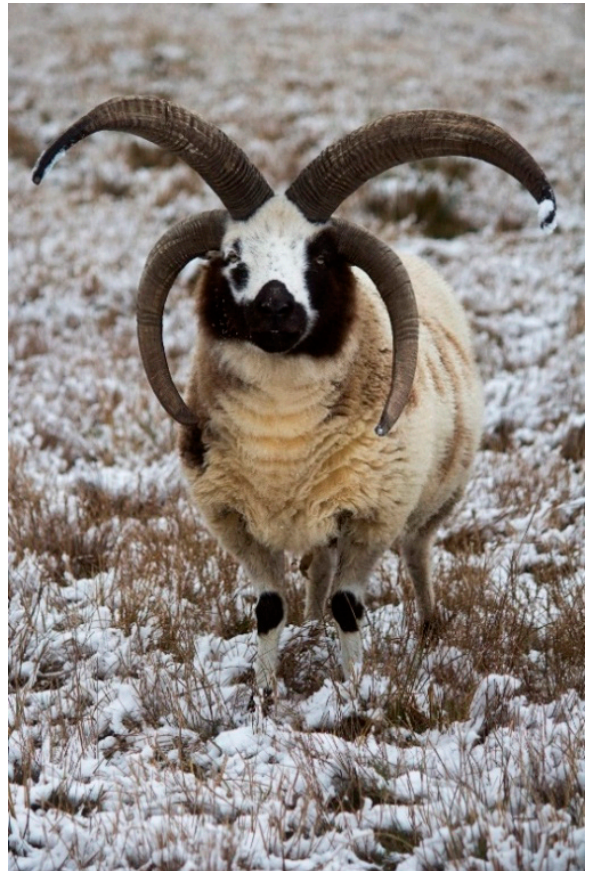

(a)

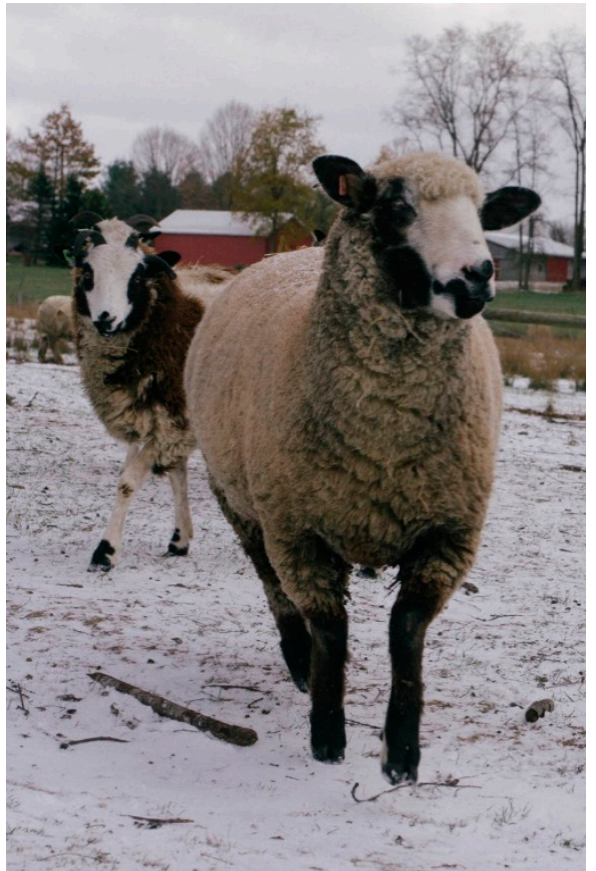

(b)

Figure 1. Jacob Sheep (a) and CVM/Romeldale Sheep (b).

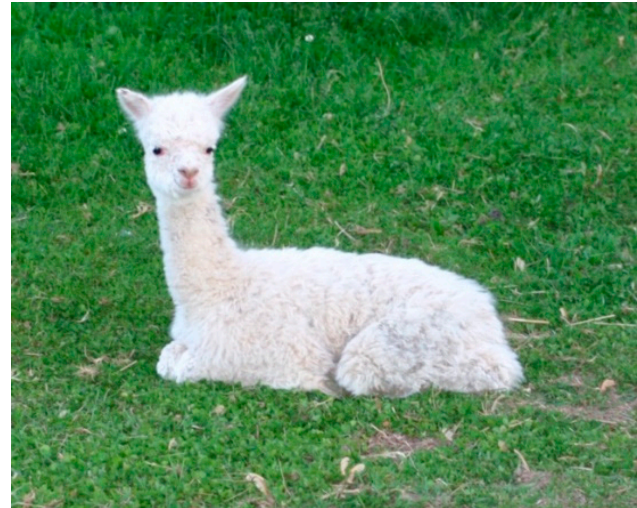

(a)

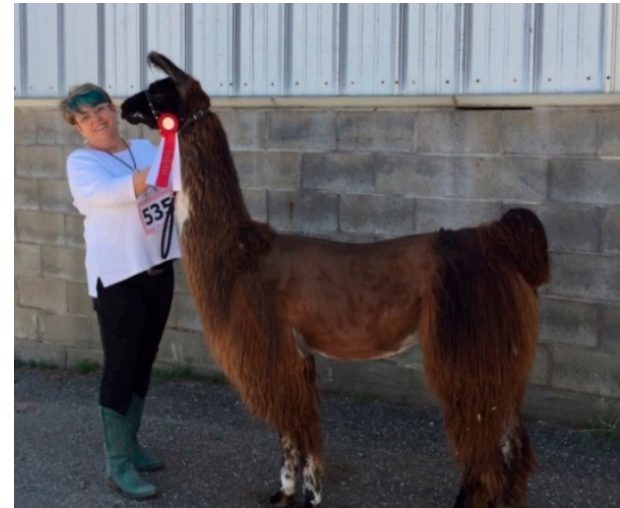

(b)

Figure 2. Alpaca (a) and Llama (b).

These yarns were chosen because of their availability as undyed yarns, for their known processing pedigrees (basic cleaning, no bleaching), and for the certainty that the fibers came from single breeds; this last was assured by purchasing the yarns directly from owners of the animal breeds mentioned above. Understanding how they were processed was critical, as processing a natural fiber will affect its flammability [1], and so only yarns that could be proven to be unbleached and minimally processed were selected and purchased for this study. Since the fibers were already spun into yarns, hand knitting was chosen to make textile specimens for flammability measurements of heat release and vertical flame spread. Yarns from single breeds and single species are not common, and when available, come in different weights, making exact comparisons difficult. Compromises were made in this paper to minimize these variances, including knitting with slightly different needles to compensate for yarn variations. 


\section{Materials and Methods}

The fabrics in this report (Figures 3-5) were hand knit using slightly different size needles in an effort to maintain sample sizes for the cone calorimeter and vertical burn tests. All samples were hand knit in garter stitch, and the following needle sizes were used to knit the specimens.

- Jacob (4" cone calorimeter samples): $4.5 \mathrm{~mm}$ needles

- Jacob (3" $\times 12^{\prime \prime}$ vertical burn samples): $5 \mathrm{~mm}$ needles

- Alpaca (4" cone calorimeter and $3 \times 12^{\prime \prime}$ vertical burn samples): $4.5 \mathrm{~mm}$ needles

- Alpaca/Merino (4" cone calorimeter and $3 \times 12^{\prime \prime}$ vertical burn samples): $5 \mathrm{~mm}$ needles

- Llama/Merino (4" cone calorimeter and $3 \times 12^{\prime \prime}$ vertical burn samples): $4.5 \mathrm{~mm}$ needles

- $\quad$ CVM/Romeldale (4" cone calorimeter and $3 \times 12^{\prime \prime}$ vertical burn samples): $5 \mathrm{~mm}$ needles

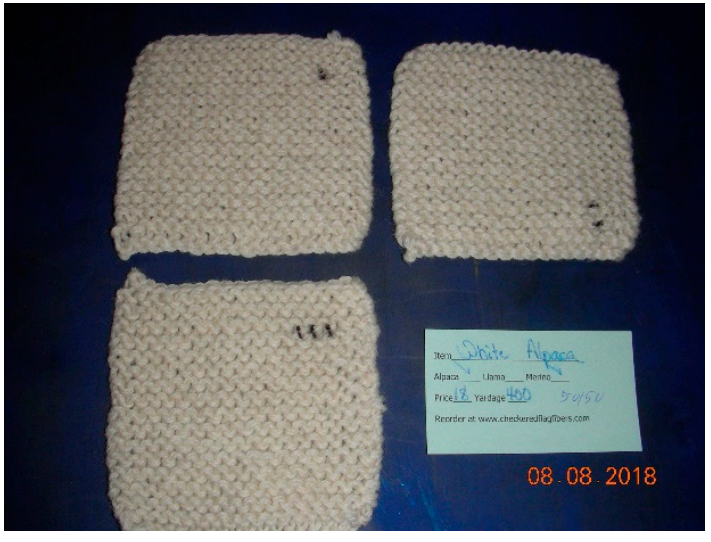

(a)

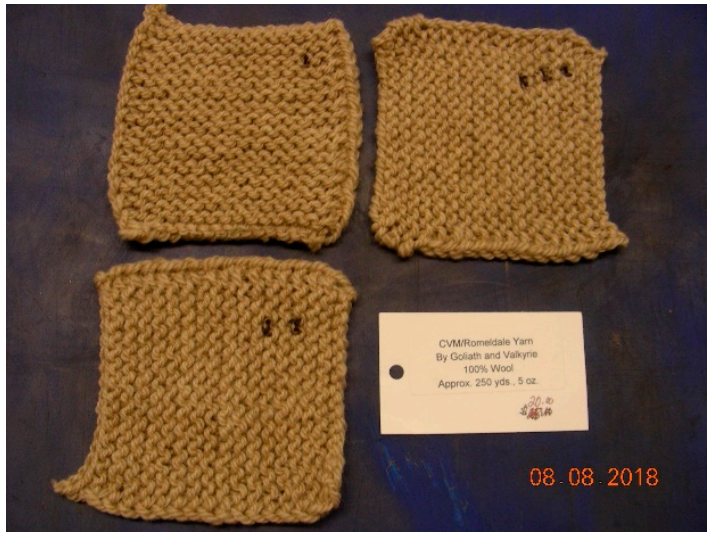

(b)

Figure 3. White Alpaca + merino wool (a) CVM Romeldale wool (b).

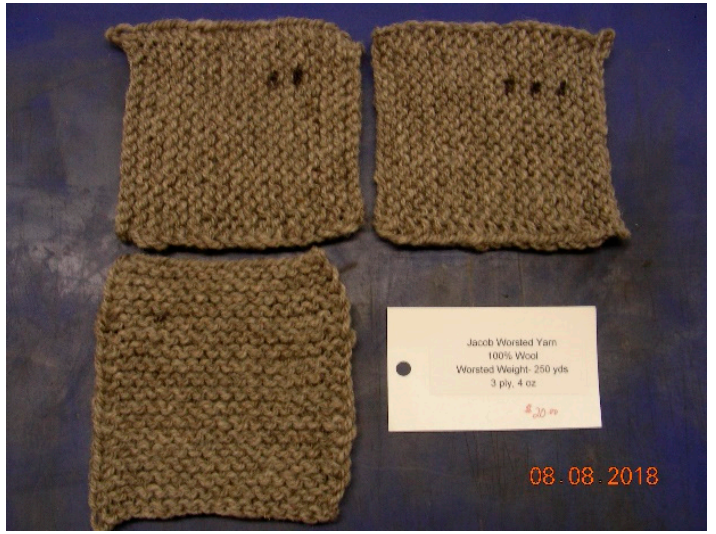

(a)

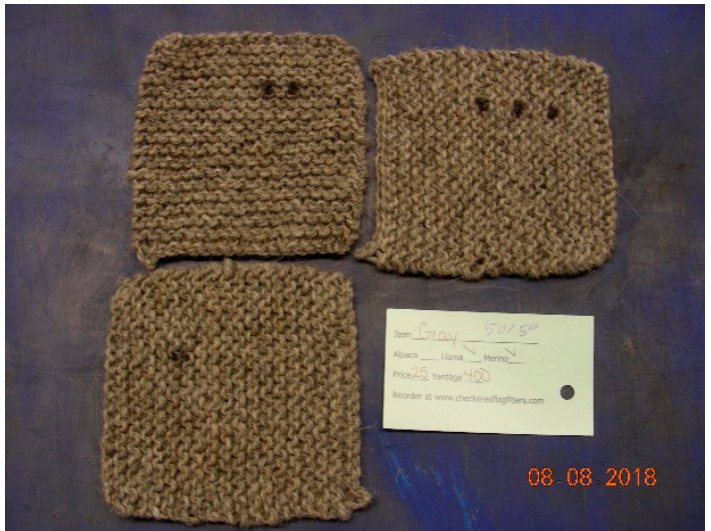

(b)

Figure 4. Jacob worsted wool (a) Grey Llama + merino wool (b). 


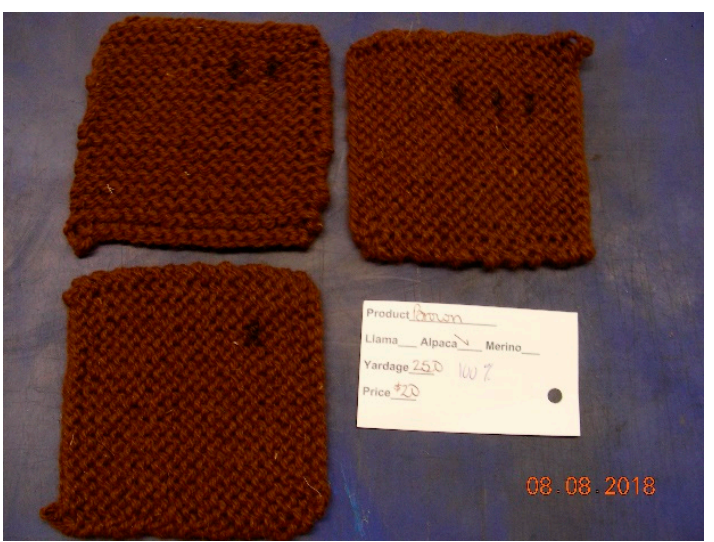

(a)

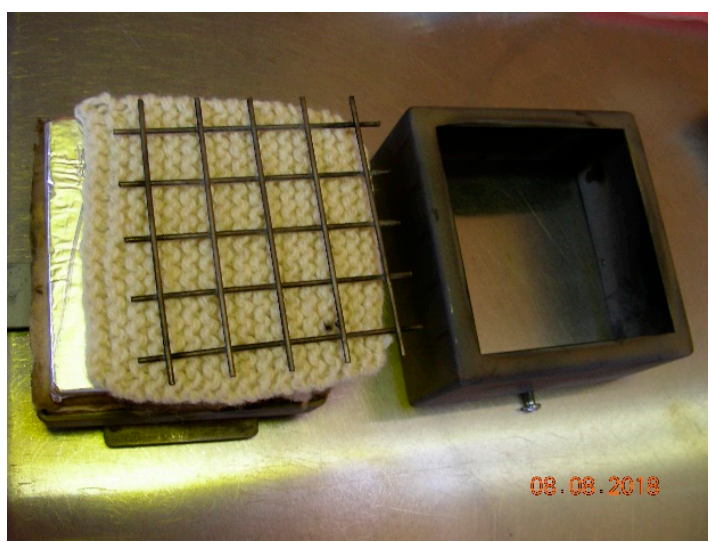

(b)

Figure 5. Brown Alpaca (a) White Alpaca in holder (b).

The Jacob and CVM/Romeldale fibers were worsted weight yarns purchased from Roving Acres Farm (Pierpont, OH, USA). The Alpaca, Alpaca/Merino, and Llama/Merino blends were sport weight yarns purchased from Checkered Flag Fibers (Springfield, OH, USA). The yarns are of different density, which is a function of their commercial availability as yarns for hand-kitting are often made available in a wide range of densities, and are not produced to one specific standard.

Cone Calorimeter experiments were conducted using a Fire Testing Technologies (FTT) Dual Cone Calorimeter at one heat flux $\left(35 \mathrm{~kW} / \mathrm{m}^{2}\right)$ with an exhaust flow of $24 \mathrm{~L} / \mathrm{s}$ using the standardized cone calorimeter procedure (ASTM E1354-16) (American Society for Testing and Materials, West cornhogan, PA, USA). Both frame and grid were used. In a slight deviation from the ASTM standard, a flat ceramic backing board was used as the underlying substrate for these tests to allow the knit fabrics to lay completely flat, and the backing board was covered in aluminum foil for this testing (Figure 5a). A fresh backing board was used for each sample to ensure to a "cold" backing surface for each sample during testing. Data collected from all samples is believed to have an error of $\pm 10 \%$ and were calculated using a specimen surface area of $88 \mathrm{~cm}^{2}$. All samples were tested in triplicate as per the ASTM E1354 standard.

Vertical burn experiments were conducted using a Govmark Vertical Flammability testing station as per ASTM D6413-15 (American Society for Testing and Materials, West cornhogan, PA, USA). The samples were not formally conditioned prior to testing, but loose strings were cut from the edges and the samples were exposed to ambient lab temperature $\left(21^{\circ} \mathrm{C}, 30 \%\right.$ to $40 \%$ relative humidity) for $24 \mathrm{~h}$ prior to testing.

Elemental analysis was conducted by Galbraith Labs (Knoxville, TN, USA) as a paid testing service.

Micro combustion calorimeter experiments were conducted with a MCC-1 (Deatak Instruments, USA) at $1{ }^{\circ} \mathrm{C} / \mathrm{sec}$ heating rate under nitrogen from 150 to $700{ }^{\circ} \mathrm{C}$ using method A of ASTM D7309-13 (American Society for Testing and Materials, USA) (pyrolysis under nitrogen). Each sample was tested in triplicate, as per the test method, to evaluate reproducibility of the flammability measurements.

Yarn and knit textile densities were obtained by cutting $1 \mathrm{~cm}$ lengths of yarn and weighing them, and weighing the cone calorimeter textile samples, along with measuring sample thickness and surface dimensions, before burning.

\section{Results}

In an effort to understand flammability differences, three different flammability techniques were chosen: Micro combustion calorimetry (ASTM D7309), cone calorimetry (ASTM E1354), and vertical flame spread testing (ASTM D6413). These tests were chosen to understand the inherent heat release from the fibers (micro combustion calorimeter), heat release from the woven fabrics (ASTM E1354), 
and effects of fiber structure and chemistry on flame spread from a spot ignition source relevant to textile fire safety (ASTM D6413). Each of the tests chosen is described below.

\subsection{Micro Combustion Calorimetry (MCC)}

Results from MCC testing of the fibers are shown in Table 1, along with a polystyrene standard for comparison. This particular test measures the inherent heat release for each yarn, and has been used previously to study the heat release of animal and plant fibers [1,15-17]. The results for the fibers studied in this work show that for wool and camelid/wool blends, the results were quite similar. However, for the $100 \%$ Alpaca fiber, notably smaller values for peak heat release rate (HRR) values and total Heat Release (HR), along with an increase in char yield, were measured. Also present in the table, is heat of complete combustion, which was calculated by dividing the total heat release by 1-measured char yield [18]. Based upon the calculated values in Table 1, the heat of complete combustion results were effectively the same regardless of fiber type. Overall, there are some minor differences in the fibers, with the $100 \%$ Alpaca fiber showing somewhat better heat release performance than the other fibers, but other than this minor difference, the fibers are effectively the same as measured by MCC.

Table 1. MCC data for wool, camelid, and camelid/wool Blends.

\begin{tabular}{cccccc}
\hline Sample & $\begin{array}{c}\text { Char } \\
\text { Yield (\%) }\end{array}$ & $\begin{array}{c}\text { HRR Peak(s) } \\
\text { Value (W/g) }\end{array}$ & $\begin{array}{c}\text { HRR Peak(s) } \\
\text { Temp(s) }\left({ }^{\circ} \mathbf{C}\right)\end{array}$ & $\begin{array}{c}\text { Total HR } \\
\mathbf{( k J / g )}\end{array}$ & $\begin{array}{c}\text { Heat of Complete } \\
\text { Combustion }\left(\mathbf{h}_{\mathbf{c}, \text { gas }}\right)\end{array}$ \\
\hline $\begin{array}{c}\text { White } \\
\text { Alpaca/Merino }\end{array}$ & 21.08 & $54,113,43$ & $303,358,421$ & 12.3 & 15.59 \\
(50/50) & 20.96 & $57,94,38$ & $304,333,437$ & 12.5 & 15.82 \\
- & 19.68 & $56,101,32$ & $290,336,392$ & 12.9 & 16.06 \\
Averages & 20.58 & - & - & 12.6 & 15.82 \\
CVM/Romeldale & 20.61 & $68,94,48$ & $311,335,412$ & 12.5 & 15.74 \\
100\% wool & 20.39 & $38,95,30$ & $318,354,431$ & 12.4 & 15.58 \\
- & 21.57 & $43,101,35$ & $321,345,438$ & 12.3 & 15.68 \\
Averages & 20.86 & - & - & 12.4 & 15.67 \\
Jacob & 20.95 & $43,99,38$ & $281,350,419$ & 12.1 & 15.31 \\
100\% wool & 21.50 & $43,88,38$ & $277,347,427$ & 12.2 & 15.54 \\
- & 21.54 & $42,90,40$ & $274,337,427$ & 12.1 & 15.42 \\
Averages & 21.33 & - & - & 12.1 & 15.42 \\
Grey & 20.34 & $56,113,27$ & $306,367,456$ & 12.6 & 15.82 \\
Llama/merino & 20.39 & $55,99,22$ & $302,356,456$ & 12.4 & 15.58 \\
(50/50) & 19.88 & $56,144,20$ & $306,358,466$ & 12.7 & 15.85 \\
- & 20.20 & - & - & 12.6 & 15.75 \\
Averages & 23.07 & $63,93,41$ & $301,356,411$ & 11.7 & 15.21 \\
Brown Alpaca & 23.95 & $57,87,36$ & $302,357,423$ & 11.8 & 15.52 \\
100\% & 23.99 & $60,98,34$ & $303,335,428$ & 11.7 & 15.39 \\
- & 23.67 & - & - & 11.7 & 15.37 \\
Averages & 0.03 & 1024 & 445 & 39.4 & 39.41 \\
Polystyrene & & 1044 & 446 & 39.0 & 39.02 \\
Standard & 0.05 & 1044 & 446 & 39.0 & 39.04 \\
- & 0.11 & - & - & 39.1 & 39.16 \\
- & 0.06 & & & &
\end{tabular}

When investigating the HRR curves from the MCC data (Figure 6), the results were also very similar, showing onsets of decomposition/HRR around $200{ }^{\circ} \mathrm{C}$, regardless of fiber type, and an end in decomposition/HRR around $650^{\circ} \mathrm{C}$. This suggests that since these animal protein fibers mostly have the same chemistry, they all begin to thermally decompose, convert to char, and finish carbonizing at the same rate. Further, all of these fibers showed a general behavior between 300 to $400{ }^{\circ} \mathrm{C}$ where the HRR data was very irregular and "noisy", which was due to the bubbling/boiling of the liquified fibers as they carbonized and charred. Therefore, the recorded values of the peak HRR should not be viewed as absolute measurements, but rather as a range of HRR values that occurred as the animal fibers thermally decomposed. Final chars (Figure 7) for the animal fibers tested were effectively identical, 
and showed a glossy carbonized material which clearly flowed and melted and did not maintain its original fiber shape.

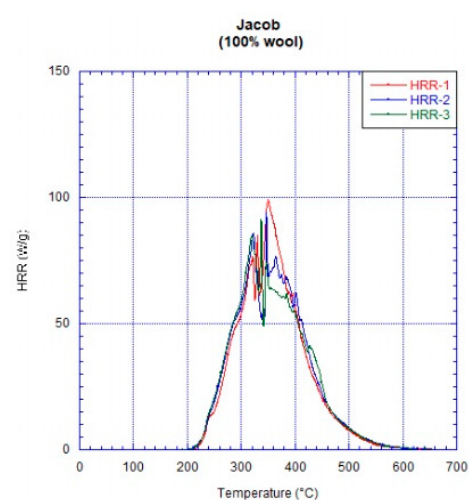

(a)

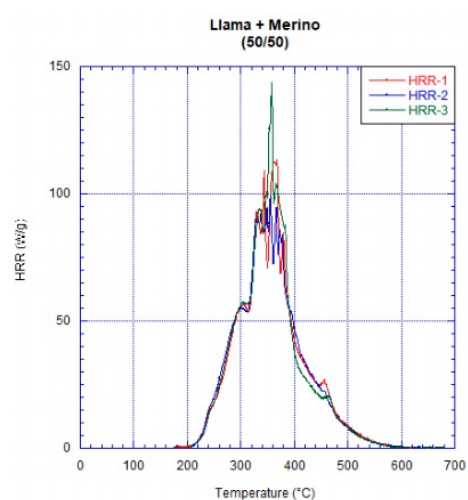

(b)

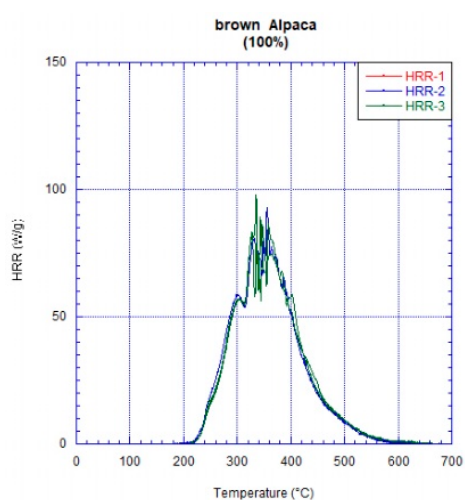

(c)

Figure 6. HRR curves for 100\% wool (Jacob) (a), 50/50 Llama/Merino (b), and 100\% Alpaca (c).

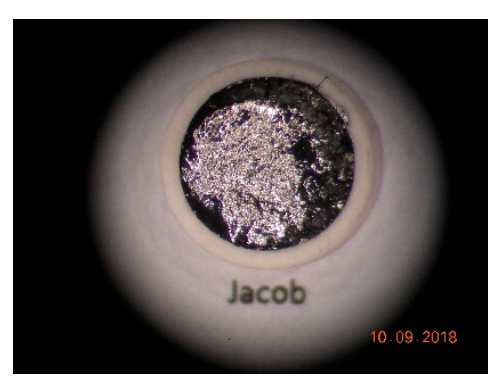

(a)

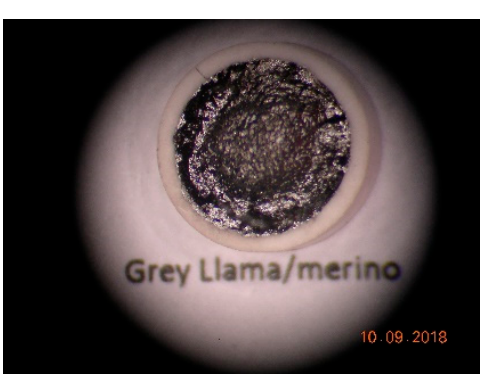

(b)

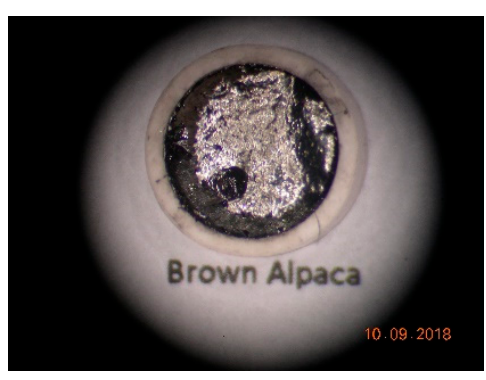

(c)

Figure 7. Char pictures for $100 \%$ wool (Jacob) (a), 50/50 Llama/Merino (b), and 100\% Alpaca (c).

\subsection{Cone Calorimetry}

Cone calorimeter is a larger scale heat release test when compared to the MCC. Like the MCC, it measures the inherent heat release of materials, but as a function of sample thickness, geometries, and construction. It has successfully been used to study the heat release of textiles [19-21], but not hand-knit textiles. Cone calorimeter may observe some heat release differences as a function of knitted density, since each of the animal fibers knit up differently, especially those of slightly different weight (worsted vs. sport weight).

When tested, all of the samples showed the same general fire behavior. Upon exposure to the cone heater, all samples began to emit some white smoke. The sample would char and simultaneously liquify/boil before igniting. There were usually two smoke peaks; the samples did not smoke much during the initial flaming phase, so some of the smoke was from pre-ignition behavior, and the rest of the smoke "burned off" once the fabrics ignited. During burning, the samples eventually stopped boiling and set up into final chars, and the residual pyrolysis gases from the samples burned off. The final chars were not very different between the five samples, showing melting/charring behavior in the final chars left behind from testing. Some material remained intact around the edges of the tested samples, where the metal frame protected the samples from burning (see Figures 8-12 below). In regard to HRR curve shape, there was some notable scatter in the consistency of the curve shape, which was likely due to physical phenomena of the fibers boiling/melting down into final stable chars at different rates. Very likely, localized differences in fiber density/knit density were responsible for the differences. Only the 100\% Alpaca showed consistent HRR curve shape and good reproducibility, and this may be due to the higher density of this animal fiber yarn and knit, as will be discussed later in Section 3.4 of this paper. 


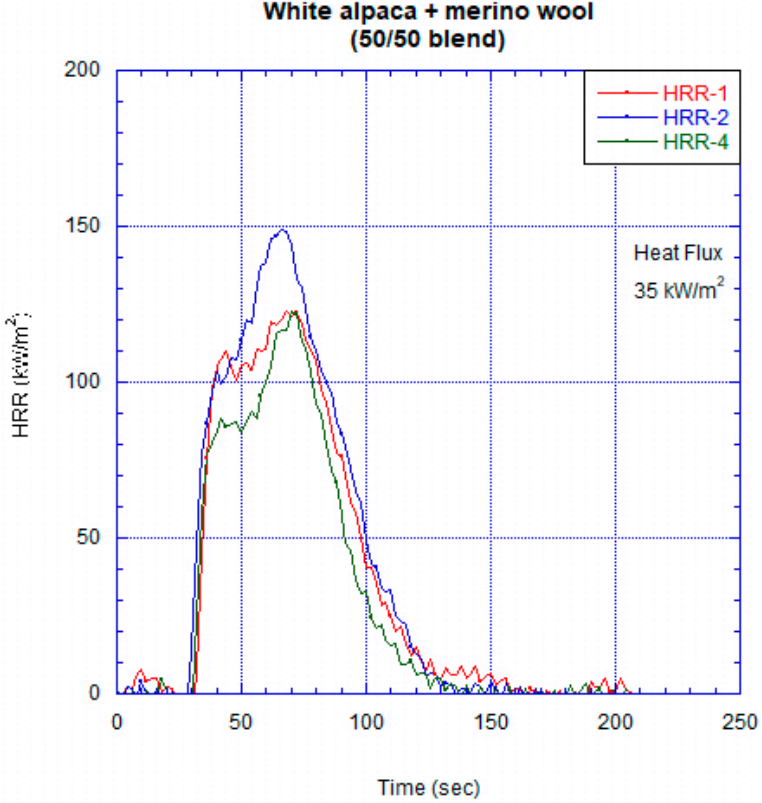

(a)

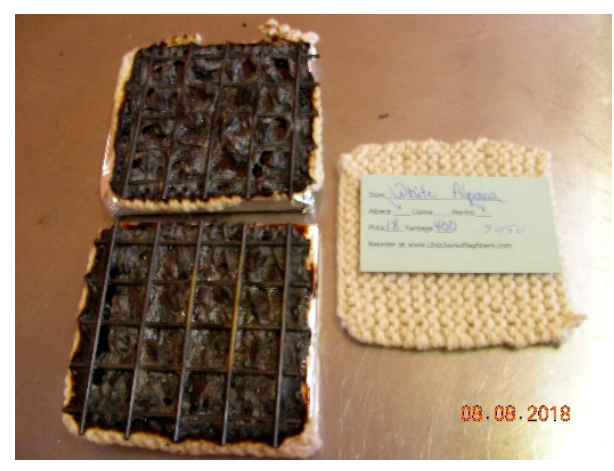

(b)

Figure 8. Heat Release Rate curve (a) and char picture (b) for White Alpaca + merino sample.

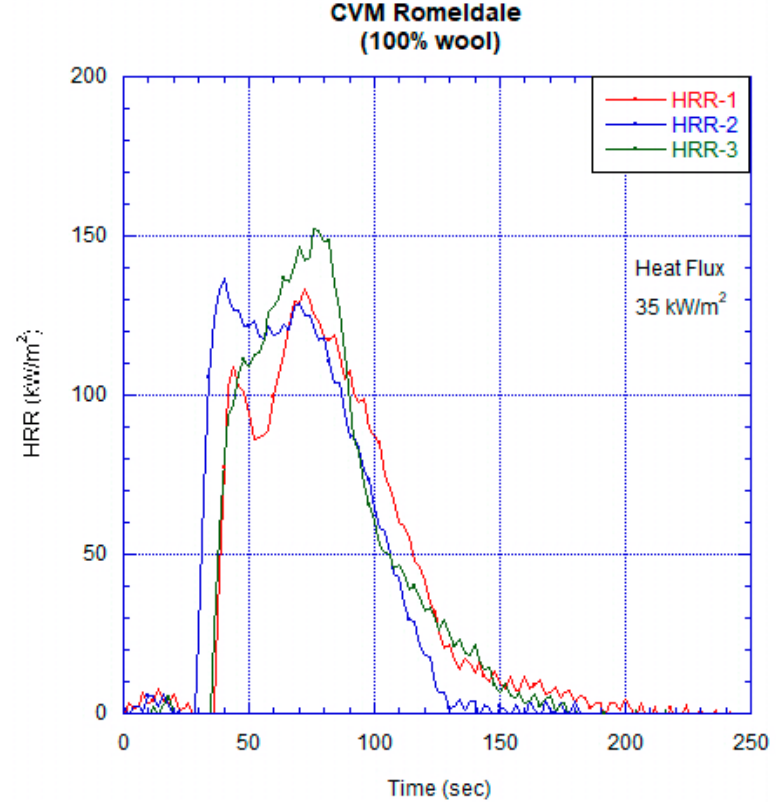

(a)

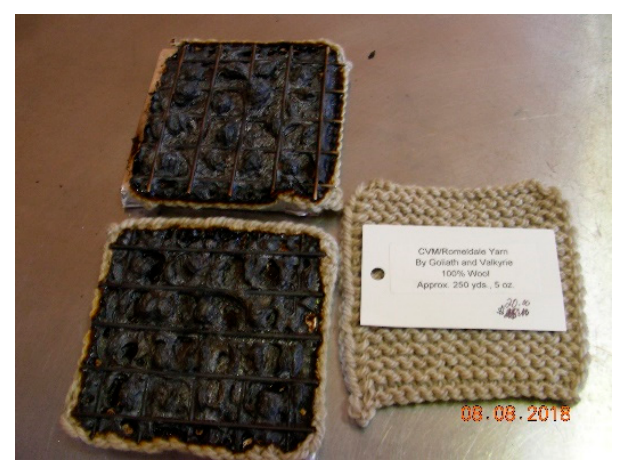

(b)

Figure 9. Heat Release Rate curve (a) and char picture (b) for CVM Romeldale sample. 


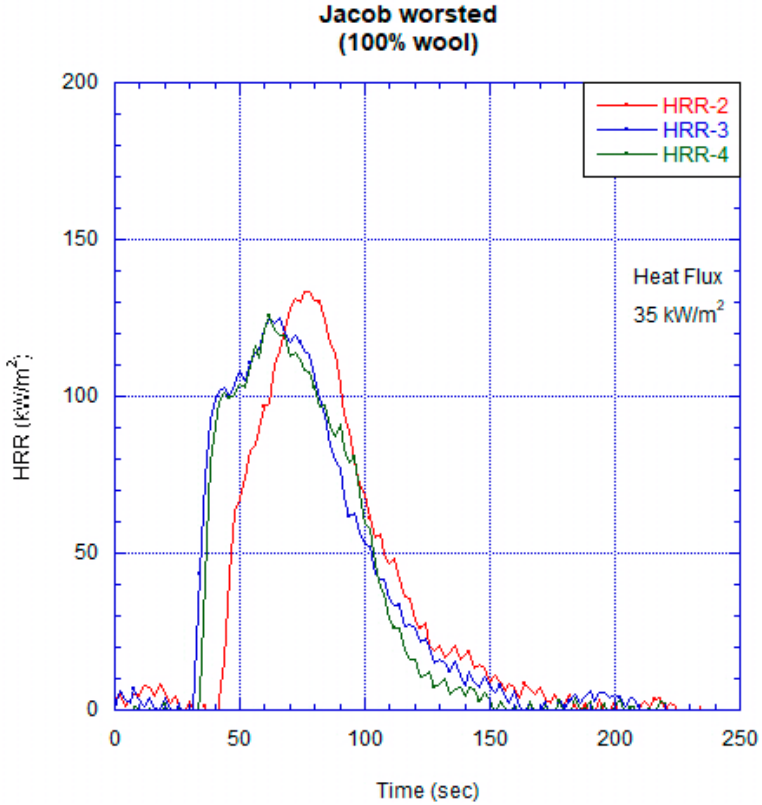

(a)

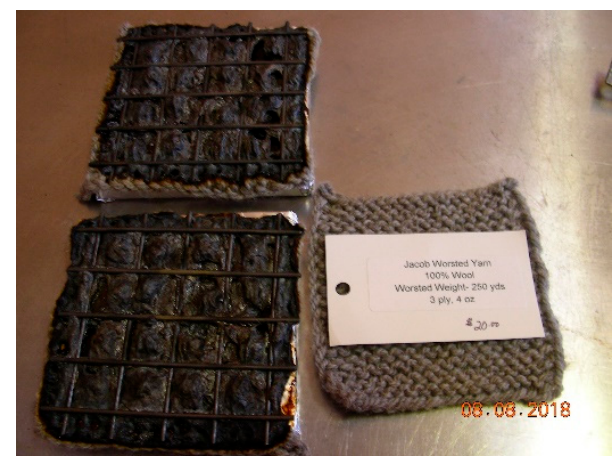

(b)

Figure 10. Heat Release Rate curve (a) and char picture (b) for Jacob worsted wool sample.

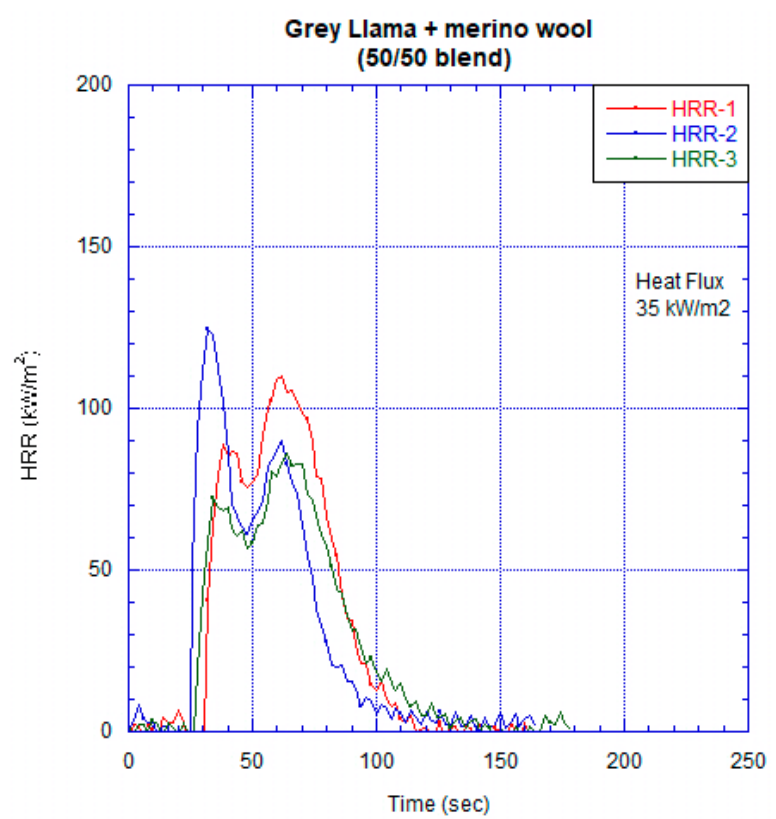

(a)

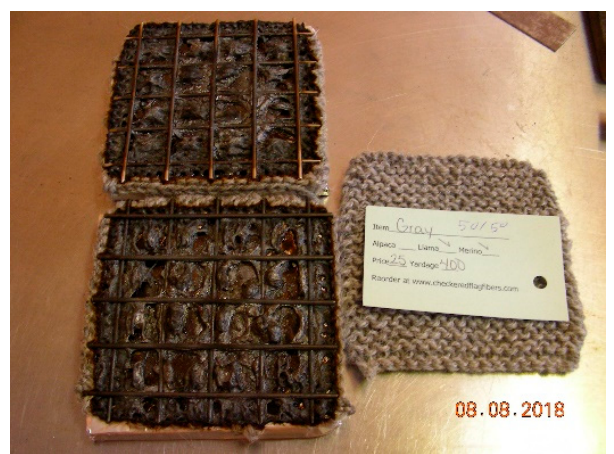

(b)

Figure 11. Heat Release Rate curve (a) and char picture (b) for Grey Llama + merino wool sample. 


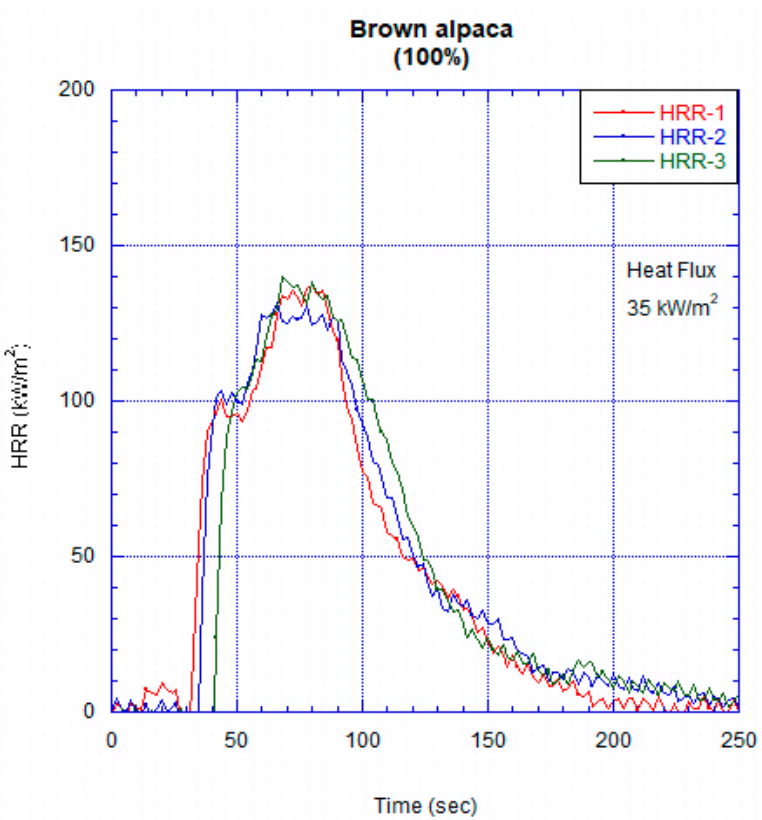

(a)

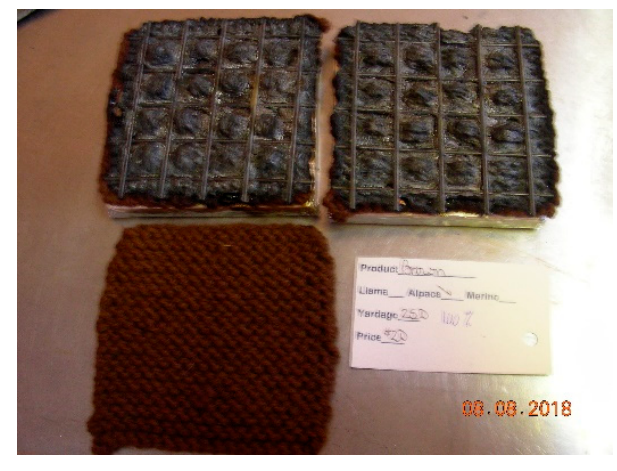

(b)

Figure 12. Heat Release Rate curve (a) and char picture (b) for Brown Alpaca sample.

From the data in Table 1, many of the samples were found to be within the $10 \%$ error for the technique, and so at first glance were not statistically different from one another. However, some differences in self-extinguishing behavior were noted in vertical flammability tests (discussed later in this report), so the materials clearly had some difference in fire behavior, but it was not as readily apparent from the cone calorimeter data. Therefore, in radiant heat source tests, such as the cone calorimeter, there may be some minor differences between animal fiber types, but nothing significant at the heat flux used in these reported experiments. Perhaps at a lower heat flux some differences would be observed.

Finally, some additional commentary is needed on the differences in \% char yields measured for the samples in the cone calorimeter vs. those measured in the MCC technique in Table 1 . The fibers tested via MCC were pyrolyzed up to high temperature $\left(700^{\circ} \mathrm{C}\right)$ in an open crucible whereas in the cone calorimeter test, the knitted fabrics were tested via a metal frame and grid, which covered some of the fibers from thermal damage. This metal frame protected the fibers from full pyrolysis, which can be seen clearly in Figures 8 and 9 below for the final chars that were photographed after testing. The metal frame protected fibers for all samples tested at the edges of the knit fabrics, but this is more obviously seen in Figures 8 and 9 due to the lighter color yarn in contrast to the black char that was generated. However, this metal frame does not explain all of the weight loss differences when looking at the char yields in Table 1, which show wt $\%$ losses of $\sim 76 \%$ to $80 \%$, vs. ranges of $\sim 25 \%$ to $39 \%$ in the cone calorimeter. This large difference in mass loss indicates that the materials in the cone calorimeter were not as fully pyrolyzed/decomposed as those in the MCC experiments, and therefore the Heat of Complete Combustion values in the MCC experiments in Table 1 were notably different than the average Effective Heat of Combustion values from Cone Calorimeter experiments in Table 2. 
Table 2. $35 \mathrm{~kW} / \mathrm{m}^{2}$ Heat flux exposure-cone calorimeter data for Animal fiber knit fabric samples. MARHE: Maximum Average Rage of Heat Emission; FIGRA: Fire Growth Rate.

\begin{tabular}{|c|c|c|c|c|c|c|c|c|c|c|c|c|c|c|c|}
\hline $\begin{array}{l}\text { Sample } \\
\text { ID \# } \\
-\end{array}$ & $\begin{array}{c}\text { Sample } \\
\text { Description } \\
-\end{array}$ & $\begin{array}{l}\text { Sample } \\
\text { Thickness } \\
(\mathrm{mm})\end{array}$ & $\begin{array}{l}\text { Time to } \\
\text { Ignition } \\
\text { (s) }\end{array}$ & $\begin{array}{c}\text { Peak } \\
\text { HRR } \\
\left(\mathrm{kW} / \mathrm{m}^{2}\right)\end{array}$ & $\begin{array}{l}\text { Time to } \\
\text { Peak HRR } \\
\text { (s) }\end{array}$ & $\begin{array}{l}\text { Time to Peak } \\
\text { HRR-Tig } \\
\text { (s) }\end{array}$ & $\begin{array}{c}\text { Average } \\
\text { HRR } \\
\left(\mathrm{kW} / \mathrm{m}^{2}\right)\end{array}$ & $\begin{array}{l}\text { Starting } \\
\text { Mass } \\
\text { (g) }\end{array}$ & $\begin{array}{l}\text { Total Mass } \\
\text { Loss } \\
\text { (g) }\end{array}$ & $\begin{array}{l}\text { Weight } \\
\text { Lost } \\
(\%)\end{array}$ & $\begin{array}{l}\text { Total Heat } \\
\text { Release } \\
\left(\mathrm{MJ} / \mathrm{m}^{2}\right)\end{array}$ & $\begin{array}{l}\text { Total Smoke } \\
\text { Release } \\
\left(\mathrm{m}^{2} / \mathrm{m}^{2}\right)\end{array}$ & $\begin{array}{c}\text { Average Effective } \\
\text { Heat of Combustion } \\
\text { (MJ/kg) }\end{array}$ & $\begin{array}{l}\text { MARHE } \\
\left(\mathrm{kW} / \mathrm{m}^{2}\right)\end{array}$ & $\begin{array}{c}\text { FIGRA } \\
\left(\mathrm{kW} / \mathrm{m}^{2} / \mathrm{s}\right)\end{array}$ \\
\hline $\begin{array}{l}\text { white } \\
\text { alpaca }\end{array}$ & $50 / 50$ blend & 6.5 & 27 & 123 & 68 & 41 & 59 & 7.6 & 2.1 & 27.4 & 7.3 & 20 & 31.21 & 67 & 1.81 \\
\hline merino & - & 6.5 & 23 & 149 & 66 & 43 & 82 & 7.3 & 2.3 & 31.6 & 8.1 & 30 & 31.27 & 75 & 2.26 \\
\hline - & - & 6.5 & 22 & 126 & 38 & 16 & 58 & 6.8 & 1.9 & 28.0 & 6.7 & 14 & 30.72 & 67 & 3.31 \\
\hline - & - & 6.5 & 25 & 123 & 70 & 45 & 59 & 6.6 & 1.7 & 25.2 & 6.1 & 23 & 32.77 & 60 & 1.75 \\
\hline - & Average Data & 6.5 & 25 & 132 & 68 & 43 & 67 & 7.2 & 2.0 & 28.1 & 7.2 & 24 & 31.75 & 67 & 1.94 \\
\hline $\begin{array}{l}\text { CVM } \\
\text { Romeldale }\end{array}$ & $100 \%$ wool & 6.5 & 29 & 152 & 76 & 47 & 67 & 9.3 & 2.7 & 28.7 & 9.0 & 21 & 30.02 & 74 & 2.01 \\
\hline- & - & 6.5 & 24 & 137 & 40 & 16 & 86 & 6.5 & 2.6 & 39.4 & 8.7 & 15 & 29.79 & 79 & 3.42 \\
\hline - & - & 6.5 & 31 & 133 & 72 & 41 & 54 & 9.4 & 2.7 & 28.8 & 8.7 & 24 & 29.01 & 68 & 1.85 \\
\hline - & Average Data & 6.5 & 28 & 141 & 63 & 35 & 69 & 8.4 & 2.6 & 32.3 & 8.8 & 20 & 29.61 & 74 & 2.42 \\
\hline $\begin{array}{c}\text { Jacob } \\
\text { worsted }\end{array}$ & $100 \%$ wool & 6.5 & 17 & 140 & 32 & 15 & 64 & 8.0 & 2.1 & 25.7 & 6.8 & 6 & 28.90 & 67 & 4.38 \\
\hline - & - & 6.5 & 38 & 133 & 78 & 40 & 52 & 8.1 & 2.2 & 27.6 & 7.3 & 16 & 28.81 & 58 & 1.71 \\
\hline - & - & 6.5 & 27 & 125 & 62 & 35 & 63 & 8.3 & 2.3 & 27.9 & 7.8 & 20 & 30.24 & 67 & 2.02 \\
\hline - & - & 6.5 & 29 & 125 & 62 & 33 & 56 & 7.9 & 2.2 & 27.4 & 7.4 & 21 & 29.98 & 65 & 2.02 \\
\hline - & Average Data & 6.5 & 31 & 128 & 67 & 36 & 57 & 8.1 & 2.2 & 27.6 & 7.5 & 19 & 29.68 & 63 & 1.92 \\
\hline $\begin{array}{c}\text { Grey } \\
\text { Llama }\end{array}$ & $50 / 50$ blend & 6.0 & 25 & 110 & 62 & 37 & 63 & 5.6 & 1.5 & 27.3 & 5.1 & 17 & 29.61 & 55 & 1.77 \\
\hline merino & - & 6.0 & 20 & 124 & 32 & 12 & 52 & 5.2 & 1.4 & 26.2 & 4.5 & 13 & 29.27 & 55 & 3.88 \\
\hline- & & 6.0 & 23 & 86 & 64 & 41 & 48 & 5.4 & 1.5 & 27.2 & 4.5 & 15 & 27.77 & 45 & 1.34 \\
\hline - & Average Data & 6.0 & 23 & 107 & 53 & 30 & 54 & 5.4 & 1.4 & 26.9 & 4.7 & 15 & 28.88 & 52 & 2.33 \\
\hline $\begin{array}{l}\text { Brown } \\
\text { alpaca }\end{array}$ & $100 \%$ & 6.5 & 28 & 137 & 80 & 52 & 59 & 10.6 & 3.0 & 28.1 & 10.2 & 18 & 30.17 & 75 & 1.72 \\
\hline- & - & 6.5 & 29 & 132 & 66 & 37 & 58 & 10.4 & 3.2 & 31.0 & 10.7 & 30 & 29.50 & 74 & 1.99 \\
\hline - & - & 6.5 & 35 & 140 & 68 & 33 & 57 & 10.5 & 3.5 & 33.7 & 10.6 & 32 & 26.78 & 72 & 2.06 \\
\hline - & Average Data & 6.5 & 31 & 136 & 71 & 41 & 58 & 10.5 & 3.2 & 30.9 & 10.5 & 27 & 28.82 & 74 & 1.92 \\
\hline
\end{tabular}




\subsection{Vertical Burn Testing}

Traditionally, vertical burn flammability tests are used for textiles to understand flame spread and the potential risks and hazards for people wearing said fabrics, and vertical burn tests such as ASTM D6413 are often used for regulatory purposes for such fabrics, whether machine or hand knit.

The vertical burn results, unlike the cone calorimeter results, differentiate more between the fiber types, and the results suggest that animal fiber source, which affects the density of the knit, may play a role in the vertical flame spread behavior and whether the samples self-extinguish once exposed to flame. The overall burn results are shown in Table 3. Based upon the results, the $100 \%$ Alpaca blend showed excellent self-extinguishing behavior, as did the CVM/Romeldale. The other materials showed erratic results or poor self-extinguishing behavior. From the ASTM method, the standard deviation in char length for machine woven fabrics was 0.566 inches, and the standard deviation for afterflame times was $0.23 \mathrm{~s}$. The results in Table 3 are significantly different, but there was admittedly a lot of irregular burning behavior for some of the samples tested. The results suggest that animal fiber type does play a role in self-extinguishing behavior, which may be more due to the density of the knit. Specifically, animal fibers which produce denser knits/yarns may impart better self-extinguishing behavior in the vertical burn test. There are irregular results for some of the knit fabrics which we cannot fully explain at this time. We hypothesize that the inconsistent results are likely due to localized effects in the knit density/fiber density between the hand-knit items. While experienced knitters can produce consistent knit density in hand-knit items, if the yarn used for knitting is inconsistent in density or "tightness" of the spun yarn, the hand-knit fabric may have localized density variations which would burn/char differently, which would in turn affect vertical flame spread. This fiber density could be due to the morphology and shape of the fibers from each animal fiber, which would affect its density and ability to be spun into a loose or dense yarn. 
Table 3. Vertical burn (ASTM D6413) data for animal fiber knit fabric samples.

\begin{tabular}{|c|c|c|c|c|}
\hline Sample & Burn Time & Burn Length (Inches) & Burn Length (cm) & Notes \\
\hline White Alpaca/Merino (50\%/50\%) \#1 & $1 \mathrm{~min}, 7 \mathrm{~s}$ & Burn to Clamp & $12^{\prime \prime}$ & Seemed that pilot flame reignited sample \\
\hline White Alpaca/Merino (50\%/50\%) \#2 & $11 \mathrm{~s}$ & $4-1 / 4^{\prime \prime}$ & 10.7 & - \\
\hline White Alpaca/Merino (50\%/50\%) \#3 & $1 \mathrm{~min}, 29 \mathrm{~s}$ & Burn to Clamp & $12^{\prime \prime}$ & Seemed that pilot flame reignited sample \\
\hline CVM/Romeldale Wool (100\%) \#1 & 0 & $2-1 / 2^{\prime \prime}$ & 6.3 & Self extinguished rapidly \\
\hline CVM/Romeldale Wool (100\%) \#2 & 0 & $2-1 / 2^{\prime \prime}$ & 6.3 & Self extinguished rapidly \\
\hline CVM/Romeldale Wool $(100 \%) \# 3$ & 0 & $3-1 / 2^{\prime \prime}$ & 8.2 & Self extinguished rapidly \\
\hline Jacob Wool $(100 \%) \# 1$ & $1 \mathrm{~min}, 27 \mathrm{~s}$ & Burn to Clamp & $12^{\prime \prime}$ & - \\
\hline Jacob Wool (100\%) \#2 & 1 & $3^{\prime \prime}$ & 7.5 & $\begin{array}{l}\text { Self extinguished, but not right away. } \\
\text { May have been able to re-ignite if flame } \\
\text { applied for just a few more seconds. }\end{array}$ \\
\hline Jacob Wool (100\%) \#3 & $1 \mathrm{~min}, 8 \mathrm{~s}$ & Burn to Clamp & $12^{\prime \prime}$ & 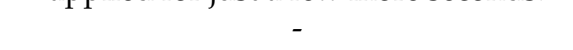 \\
\hline Grey Llama/Merino (50\%/50\%) \#1 & $59 \mathrm{~s}$ & Burn to Clamp & $12^{\prime \prime}$ & $\begin{array}{l}\text { Burned up quickly } \\
\text { Self extinguished. Unclear if it would }\end{array}$ \\
\hline Grey Llama/Merino (50\%/50\%) \#2 & 0 & $3-3 / 4^{\prime \prime}$ & 9.5 & $\begin{array}{l}\text { have easily reignited - not sure why } \\
\text { different than the other samples. }\end{array}$ \\
\hline Grey Llama/Merino (50\%/50\%) \#3 & $47 \mathrm{~s}$ & Burn to Clamp & $12^{\prime \prime}$ & Burned up quickly \\
\hline Brown Alpaca $(100 \%) \# 1$ & 0 & $1-1 / 2^{\prime \prime}$ & 3.8 & Self extinguished rapidly \\
\hline Brown Alpaca $(100 \%) \# 2$ & 0 & $1-1 / 2^{\prime \prime}$ & 3.8 & Self extinguished rapidly \\
\hline Brown Alpaca $(100 \%) \# 3$ & 0 & $1^{\prime \prime}$ & 2.5 & Self extinguished rapidly \\
\hline
\end{tabular}


Observed fire behavior for each of the samples tested is described in Table 3, and the samples before and after burning are shown in Figures 13-17.

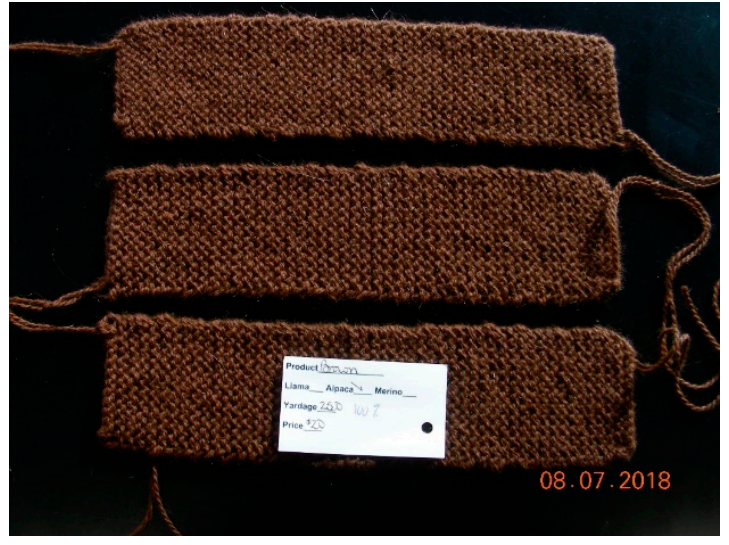

(a)

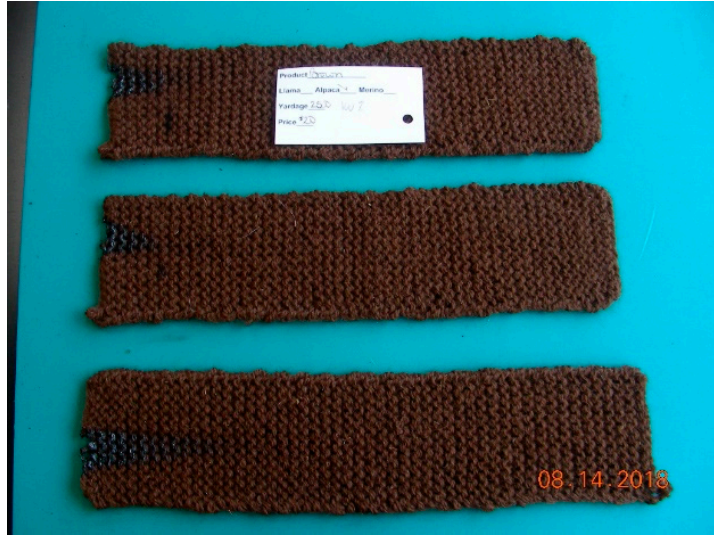

(b)

Figure 13. Brown 100\% Alpaca Vertical Burn-before testing (a) and after testing (b).

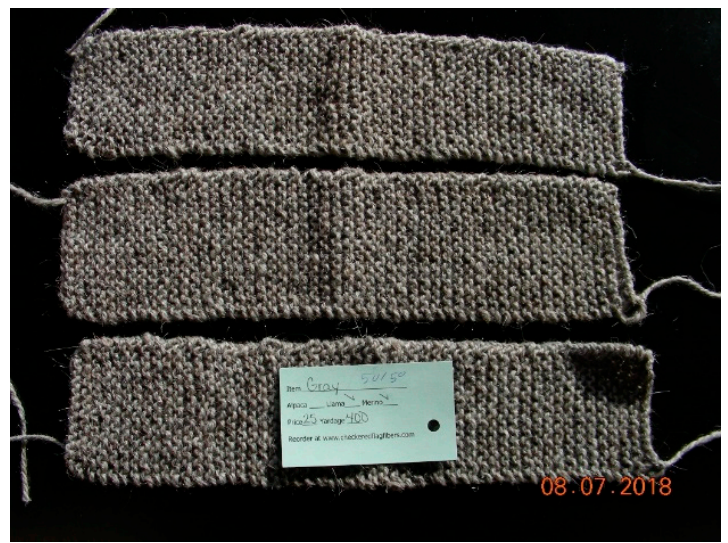

(a)

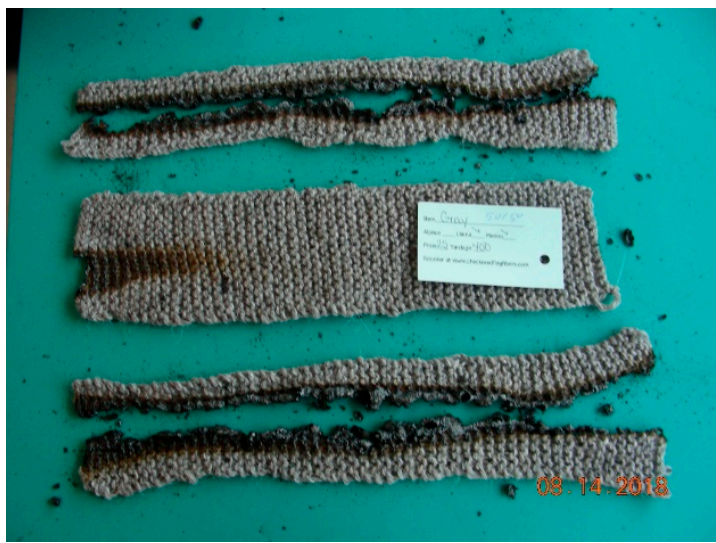

(b)

Figure 14. Llama/Merino Blend Vertical Burn-before testing (a) and after testing (b).

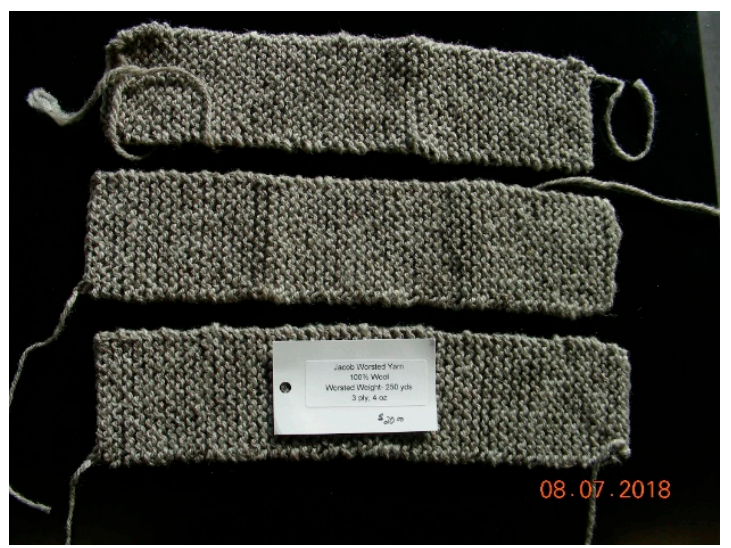

(a)

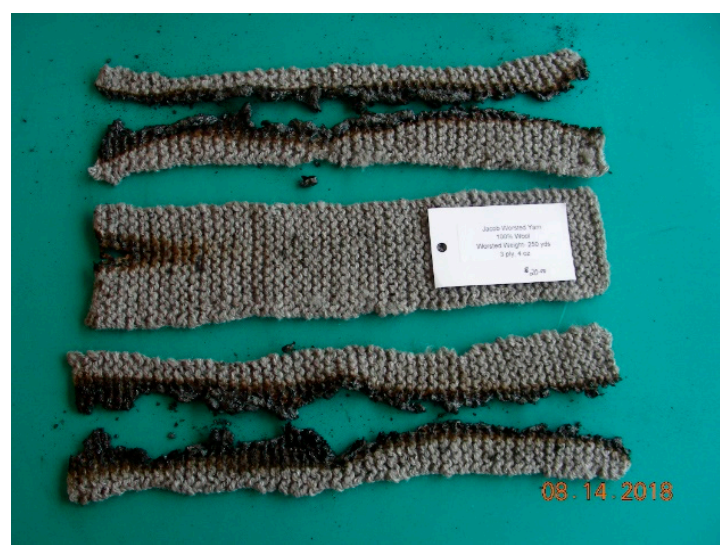

(b)

Figure 15. Jacob Wool Vertical Burn-before testing (a) and after testing (b). 


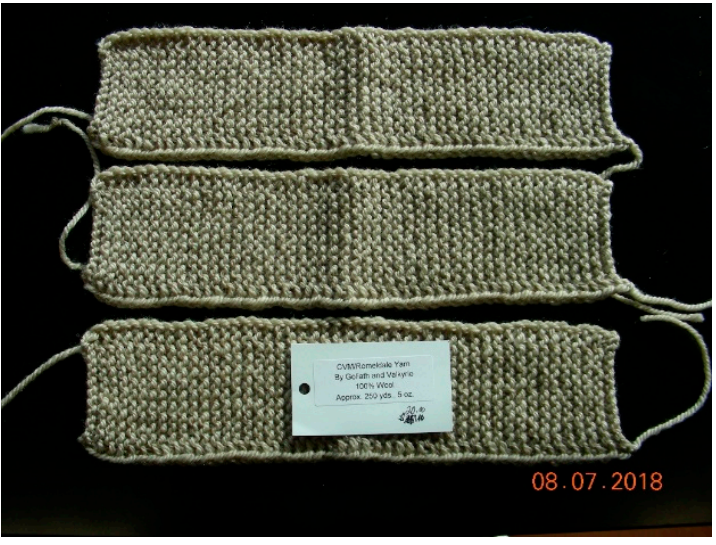

(a)

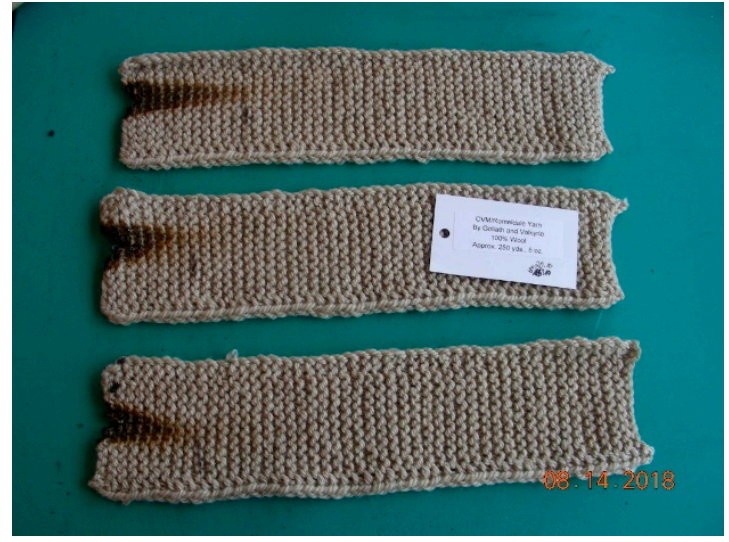

(b)

Figure 16. CVM/Romeldale Blend Vertical Burn-before testing (a) and after testing (b).

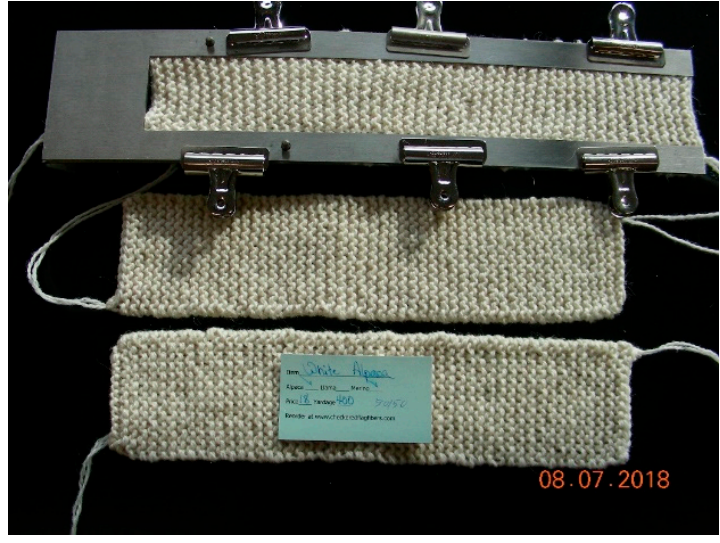

(a)

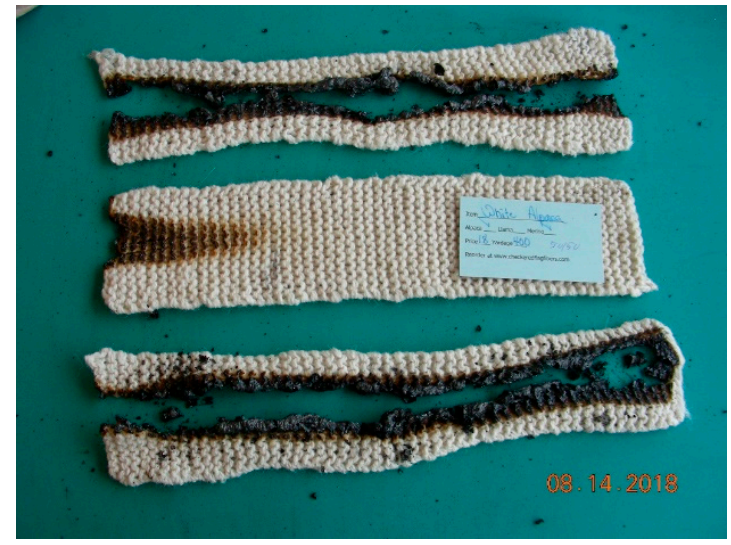

(b)

Figure 17. Alpaca/Merino Blend Vertical Burn-before testing (a) and after testing (b). [note sample in metal sample holder prior to testing].

\subsection{Animal Fiber Analysis}

In an effort to better understand why the animal fiber samples burned the way they did, and why the flammability measurements did not give results which explained/complimented one another, some detailed analysis on the yarns and fibers themselves were carried out. This included elemental analysis, fiber density/fabric areal weight, and fiber structure.

\subsubsection{Animal Fiber Analysis: Elemental Analysis}

Animal fiber flammability is known to be affected by sulfur content. Methionine and cysteine ${ }^{2}$ form S-S bonds between polypeptide chains in the fiber structure, which in turn enable faster char formation [22]. Elemental analysis was conducted to look for variations in sulfur content between fibers to determine differences in sulfur content vs. the known 3\% to $4 \%$ typically found in wool fibers [2]. The results from elemental analysis which studied $\mathrm{C}, \mathrm{H}, \mathrm{N}, \mathrm{O}$, and $\mathrm{S}$, are shown in Table 4. The results indicate that for the wool fibers, the sulfur content was within expected ranges, and did not vary greatly between specific breeds of sheep (compare CVM/Romeldale to Jacob). However, the Alpaca and Llama/Merino blends showed higher sulfur content, which may suggest higher methionine/cysteine content in these animal fibers. The higher sulfur content might explain why Alpaca fiber has been shown to have a higher char yield and lower heat release than the other fibers in the MCC testing. Interestingly, some of the fibers showed some percentage that was not accounted for in the elemental analysis, suggesting that elements may be present in these samples other than $\mathrm{C}, \mathrm{H}$, $\mathrm{N}, \mathrm{O}$, and $\mathrm{S}$. At this time the authors have no hypothesis for what other elements could be present. 
The \% error for the elemental analysis conducted on these samples was not provided by the vendor of the elemental analysis, and so the calculated standard deviations in Table 4 for the measured values is based solely on the information provided, and may not be significant if the \% measurement error is higher than the calculated standard deviation.

Table 4. Elemental analysis for wool and camelid fibers.

\begin{tabular}{ccccccc}
\hline Fiber & $\mathbf{C}$ & $\mathbf{H}$ & $\mathbf{N}$ & $\mathbf{O}$ & $\mathbf{S}$ & Total \\
\hline Alpaca/Merino & 44.65 & 6.92 & 14.82 & 21.47 & 3.25 & 91.11 \\
- & 44.54 & 6.75 & 14.77 & 22.49 & 3.15 & 91.70 \\
Average & 44.60 & 6.84 & 14.80 & 21.98 & 3.20 & 91.41 \\
Standard Deviation & 0.08 & 0.12 & 0.04 & 0.72 & 0.05 & 0.30 \\
\hline CVM/Romeldale & 44.59 & 6.90 & 14.73 & 23.29 & 3.06 & 92.57 \\
- & 44.72 & 6.85 & 14.77 & 26.09 & 3.15 & 95.58 \\
Average & 44.66 & 6.88 & 14.75 & 24.69 & 3.11 & 94.08 \\
Standard Deviation & 0.09 & 0.04 & 0.03 & 1.98 & 0.05 & 0.30 \\
\hline Jacob & 44.70 & 6.89 & 14.73 & 26.14 & 3.26 & 95.72 \\
- & 44.50 & 6.98 & 14.64 & 26.93 & 3.14 & 96.19 \\
Average & 44.60 & 6.94 & 14.69 & 26.54 & 3.20 & 95.96 \\
Standard Deviation & 0.14 & 0.06 & 0.06 & 0.56 & 0.05 & 0.30 \\
\hline Llama/Merino & 44.51 & 6.74 & 14.74 & 26.15 & 3.50 & 95.64 \\
- & 44.60 & 6.57 & 14.77 & 28.61 & 3.62 & 98.17 \\
Average & 44.56 & 6.66 & 14.76 & 27.38 & 3.56 & 96.91 \\
Standard Deviation & 0.06 & 0.12 & 0.02 & 1.74 & 0.05 & 0.30 \\
\hline Alpaca & 44.75 & 6.40 & 14.70 & 23.31 & 4.02 & 93.18 \\
- & 44.63 & 6.48 & 14.64 & 26.17 & 4.05 & 95.97 \\
Average & 44.69 & 6.44 & 14.67 & 24.74 & 4.04 & 94.58 \\
Standard Deviation & 0.08 & 0.06 & 0.04 & 2.02 & 0.05 & 0.30 \\
\hline
\end{tabular}

\subsubsection{Animal Fiber Analysis: Fiber Density/Fabric Areal Weight}

One way to help explain the differences from a flammability perspective would be to compare the density of the fibers themselves. A higher density yarn would have more mass available to melt/char individual fibers together when exposed to flame vs. a lower density yarn that has more gaps (air) between individual fibers. There are two ways to study fiber/yarn density: Measure grams of fiber per unit length, or to calculate the density of the knitted fabrics used in this study based upon surface area and thickness measurements of those knitted fabrics. The results from this study are shown in Table 5 below for the base yarns and for the calculated density for the cone calorimeter samples. In Table 5, the two wools had much denser per unit length, but when knit into a fabric, did not necessarily translate into more densely knit fabrics. To some extent, when looking at the knit fabrics in Figures 3-5, the fabrics all look the same, but the Alpaca did come out as a slightly denser fabric when knit. Density of the knit fabric might help explain some of the vertical burn rates for the Alpaca, but not for the other breeds.

Table 5. Density of sheep and camelid-based yarns.

\begin{tabular}{|c|c|c|c|c|c|}
\hline \multicolumn{2}{|c|}{ Animal Fiber Densities } & \multicolumn{4}{|c|}{ Cone Calorimeter Sample Data } \\
\hline Breed & $\begin{array}{l}\text { Yarn } \\
(\mathrm{g} / \mathrm{cm})\end{array}$ & $\begin{array}{l}\text { Sample Thickness } \\
\text { (cm) }\end{array}$ & $\begin{array}{l}\text { Weight } \\
\text { (g) }\end{array}$ & $\begin{array}{l}\text { Surface Area } \\
\left(\mathrm{cm}^{2}\right)\end{array}$ & $\begin{array}{c}\text { Calculated } \\
\text { Density }\left(\mathrm{g} / \mathrm{cm}^{3}\right)\end{array}$ \\
\hline Jacob & 6.036 & 0.65 & 8.1 & 103.2 & 0.12 \\
\hline $\begin{array}{c}\text { CVM } \\
\text { Romeldale }\end{array}$ & 7.315 & 0.65 & 8.4 & 103.2 & 0.13 \\
\hline Alpaca & 3.168 & 0.65 & 10.5 & 103.2 & 0.16 \\
\hline Alpaca/Merino & 2.709 & 0.65 & 7.2 & 103.2 & 0.11 \\
\hline Llama/Merino & 3.910 & 0.60 & 5.4 & 103.2 & 0.09 \\
\hline
\end{tabular}




\subsection{Fiber Flammability Discussion}

When combining MCC data, cone calorimeter data, vertical burn, data, elemental analysis, and yarn density, the results indicate that there are differences between breeds of the same species in regard to the colors and texture of the yarns, but from a flammability perspective, the results were not so clear. When comparing CVM/Romeldale and Jacob in vertical burn testing, clearly the CVM/Romeldale was the better performing wool, but from a heat release perspective, they were not significantly different. Therefore, differences in vertical flame spread were more likely due to differences in the knit density as they cannot be explained by elemental analysis or heat release. Anecdotally, the CVM/Romeldale knit up a bit "tighter" and the individual yarn strands were noted to be closer together in both cone calorimeter and vertical burn specimens, which may be an explanation for the differences in results, but this isn't clear. Some of this can be seen qualitatively in Figures 18-20 when looking at the CVM/Romeldale (Figure 18), Llama/Merino (Figure 19), and 100\% Alpaca (Figure 20), which show smaller gaps between yarn strands for the CVM Romeldale and 100\% Alpaca samples.

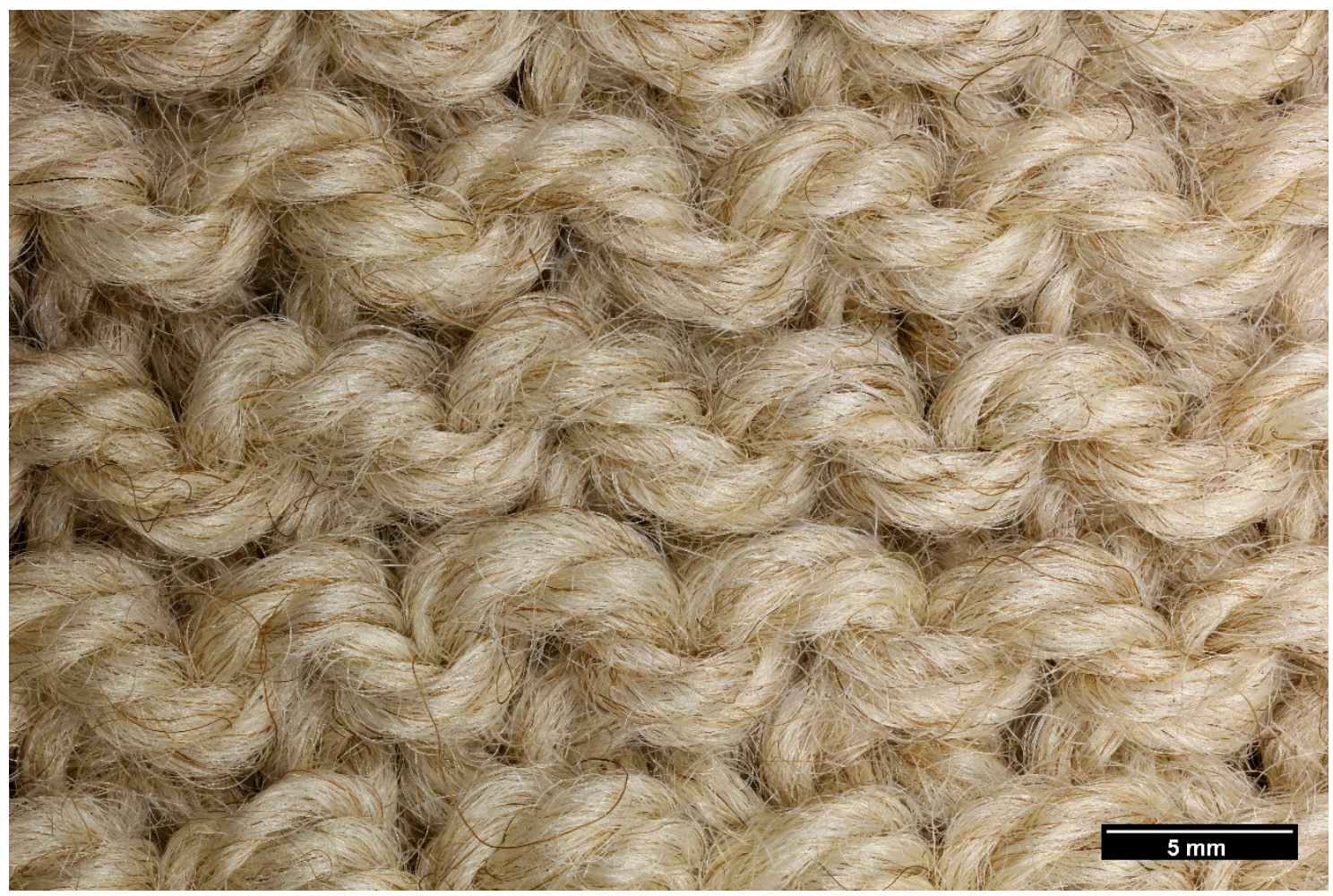

Figure 18. 1X Magnification of Knit CVM/Romeldale Yarn. 


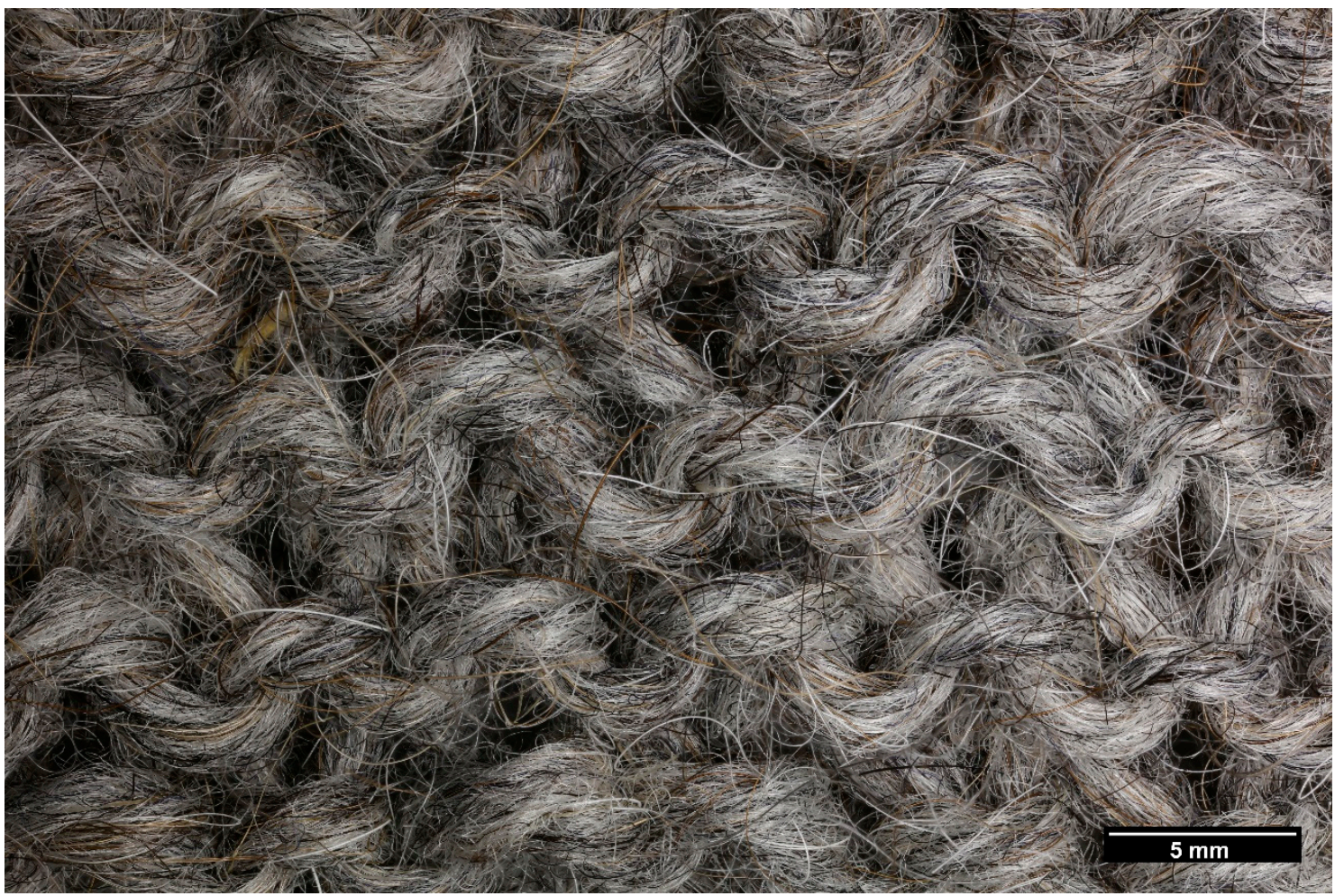

Figure 19. 1X Magnification of Knit 50/50 Llama/Merino.

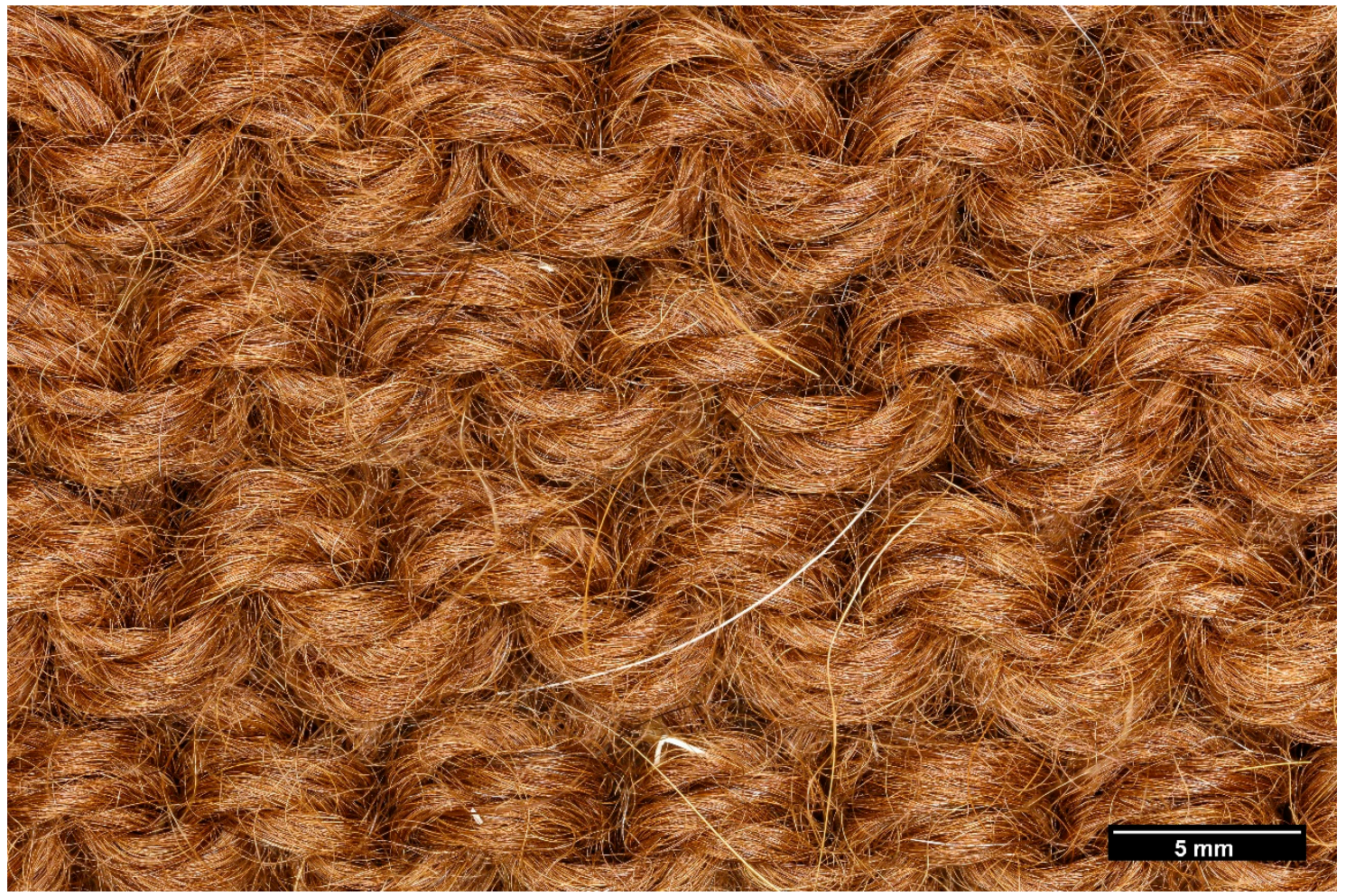

Figure 20. 1X Magnification of Knit 100\% Alpaca.

For the camelid and camelid/wool blends, the results were equally non-conclusive, except for the $100 \%$ Alpaca. The Alpaca/Merino blend and Llama/Merino blend both failed the vertical burn tests, but were not greatly different in regard to heat release, nor do they show any notable differences 
in density. The Llama/Merino showed some slightly higher sulfur content which appeared to be significant in regard to calculated standard deviation. Only the $100 \%$ Alpaca showed significantly different heat release in MCC tests that could explain vertical burn test results, but this yarn also was more densely knit, which most likely accounts for improved vertical burn tests as the chars form. Therefore, the results from the testing in this paper don't show a major difference between breeds as a function of flammability, but do show that Alpaca, with its higher sulfur content and denser knit, seems to have some inherent lower flammability when compared to the other animal fibers.

\section{Conclusions}

The flammability of yarns from different sheep and camelid breeds was studied by a variety of techniques to determine if there were fundamental differences in heat release and flammability between fibers produced by these animals. The results showed that from a heat release perspective, the yarns were not greatly different, with the exception of $100 \%$ Alpaca which had a lower heat release rate when compared to the other animal fiber yarns, and this lowered heat release may be due to the higher sulfur content of this fiber. In regard to vertical flame spread, the results were mixed, with $100 \%$ Alpaca and CVM/Romeldale breed yarns providing self-extinguishing behavior in hand-knit fabrics. The CVM/Romeldale appeared to provide a tighter and more coherent knit when knitted into a fabric, and this better structure might account for its ability to char rapidly at the ignition site and self-extinguish. 100\% Alpaca and its lower heat release and higher sulfur content could be correlated to its ability to self-extinguish in vertical flame spread tests, but its tendency to generate a tighter and more coherent knit most likely explains the self-extinguishing results. Therefore, it is a combination of animal fiber structure and density that yields self-extinguishing behavior. Specifically, fibers that spin into yarns which can give a tighter or denser knit should do better in vertical burn tests vs. those yarns/knits where the fibers are looser and not as tightly packed together.

There may be value in studying other breeds of sheep and camelids to look for higher sulfur content and lower heat release, and to further study the effects of animal breed and the type of yarns that they produce beyond the limited scope of the study in this paper. For some of the practical reasons mentioned in the introduction, 100\% Alpaca and 100\% Llama yarns are not common, and often are combined with wool to give a better balance of properties, so these may not be practical to study further. These animal fibers may yield some interesting results if combined with synthetic fibers or plant fibers where the charring effects of the animal fibers could be combined with some of the inherent charring of non-bleached plant fibers and might merit further study in that area. Finally, it would be useful to try to have single species animal fibers woven into fabrics rather than knit, to try to eliminate some of the above-mentioned spun yarn/knit fabric discrepancies. However, knowing that hand-knits will always be different from knitter to knitter, the results in this paper are still practical for fire safety of hand-knit items and indicate that looser knits and looser yarns mostly likely will have worse fire performance vs. those which are knit tighter.

Author Contributions: Conceptualization, Resources, and Writing, A.B.M.; Fiber Analysis, L.D.S. and J.D.W.; Flammability Testing, M.L.G.

Funding: This research received no external funding.

Acknowledgments: Morgan would like to thank Roving Acres Farms and Checkered Flag Fibers for their assistance in providing single breed sheep yarns and camelid/wool yarns, as well as taking the time to provide insight into how the yarns were cleaned and spun, and pictures of the animals in this report. Morgan would also like to thank Julie Ann G. Morgan for her assistance in knitting all of the cone calorimeter and vertical burn specimens in this paper.

Conflicts of Interest: The authors declare no conflict of interest.

\section{References}

1. Galaska, M.L.; Horrocks, A.R.; Morgan, A.B. Flammability of natural plant and animal fibers: A heat release survey. Fire Mater. 2017, 41, 275-288. [CrossRef] 
2. Peters, R.H. (Ed.) Textile Chemistry: The Chemistry of Fibres, Volume 1; Elsevier: Amsterdam, The Netherlands, 1963.

3. Ekarius, C.; Robson, D. The Field Guide to Fleece: 100 Sheep Breeds E How to Use Their Fibers; Storey Publishing, LLC: North Adams, MA, USA, 2013; ISBN 978-1612121789.

4. Tomes, G.L.; Robertson, D.E.; Lightfoot, R.J. (Eds.) Sheep Breeding, 2nd ed.; Elsevier: Amsterdam, The Netherlands, 1979; ISBN 978-1483162133.

5. Horrocks, A.R. Textile flammability research since 1980-Personal challenges and partial solutions. Polym. Degrad. Stab. 2013, 98, 2813-2824. [CrossRef]

6. Yang, C.Q.; He, Q.; Lyon, R.E.; Hu, Y. Investigation of the flammability of different textile fabrics using micro-scale combustion calorimetry. Polym. Degrad. Stab. 2010, 95, 108-115. [CrossRef]

7. Yang, C.Q.; He, Q. Textile heat release properties measured by microscale combustion calorimetry: Experimental repeatability. Fire Mater. 2012, 36, 127-137. [CrossRef]

8. Horrocks, A.R.; Kandola, B.K.; Davies, P.J.; Zhang, S.; Padbury, S.A. Developments in flame retardant textiles-A review. Polym. Degrad. Stab. 2005, 88, 3-12. [CrossRef]

9. Weil, E.D.; Levchik, S.V. Flame Retardants in Commercial Use or Development for Textiles. J. Fire Sci. 2008, 26, 243-281. [CrossRef]

10. Jacob sheep. Available online: https://en.wikipedia.org/wiki/Jacob_sheep (accessed on 4 October 2018).

11. Romeldale. Available online: https:/ / en.wikipedia.org/wiki/Romeldale (accessed on 4 October 2018).

12. Alpaca. Available online: https://en.wikipedia.org/wiki/Alpaca (accessed on 4 October 2018).

13. Merino. Available online: https://en.wikipedia.org/wiki/Merino (accessed on 4 October 2018).

14. Llama. Available online: https:/ / en.wikipedia.org/wiki/Llama (accessed on 4 October 2018).

15. Lyon, R.E.; Walters, R.N. Pyrolysis combustion flow calorimetry. J. Anal. Appl. Pyrolysis 2004, 71, 27-46. [CrossRef]

16. Walters, R.N.; Lyon, R.E. Molar Group Contributions to Polymer Flammability. J. Appl. Polym. Sci. 2002, 87, 548-563. [CrossRef]

17. Lyon, R.E.; Takemori, M.T.; Safronava, N.; Stoliarov, S.I.; Walters, R.N. A molecular basis for polymer flammability. Polymer 2009, 50, 2608-2617. [CrossRef]

18. Lyon, R.E.; Walter, R.N.; Stoliarov, S.I. A Thermal Analysis Method for Measuring Polymer Flammability. J. ASTM Int. 2006, 3, 1-18. [CrossRef]

19. Kandola, B.K.; Horrocks, A.R.; Padmore, K.; Dalton, J.; Owen, T. Comparison of cone and OSU calorimetric techniques to assess the flammability behavior of fabrics used for aircraft interiors. Fire Mater. 2006, 30, 241-255. [CrossRef]

20. Nazare, S.; Kandola, B.K.; Horrocks, A.R. Use of cone calorimetery to quantify the burning hazard of apparel fabrics. Fire Mater. 2002, 26, 191-200. [CrossRef]

21. Tata, J.; Alongi, J.; Carosio, F.; Frache, A. Optimization of the procedure to burn textile fabrics by cone calorimeter: Part I. Combustion behavior of polyester. Fire Mater. 2011, 35, 397-409. [CrossRef]

22. Horrocks, A.R.; Davies, P.J. Char formation in flame-retarded wool fibres. Part 1 Effect of intumescent on thermogravimetric behavior. Fire Mater. 2000, 24, 151-157. [CrossRef]

(C) 2019 by the authors. Licensee MDPI, Basel, Switzerland. This article is an open access article distributed under the terms and conditions of the Creative Commons Attribution (CC BY) license (http:// creativecommons.org/licenses/by/4.0/). 